\title{
I J IS P
}

\section{CHILDREN'S REPRESENTATIVES IN PSYCHIATRIC SERVICES: WHAT IS THE OUTCOME?}

\author{
MARGARETA ÖSTMAN \& MARIA AFZELIUS
}

\begin{abstract}
Background: Psychiatric services have established children's representatives in an effort to support children of mentally ill patients.

Material: Twenty two specially designated children's representatives and 19 other staff members were asked how they conceived the role of children's representatives and if those representatives had the responsibility of identifying children of mentally ill patients.
\end{abstract}

Discussion: Children's representatives expressed difficulty in functioning as advocates for children whose parents were being treated for mental illness. Members of the psychiatric staff, although aware their patients had children, seldom met them since they focused on the adults.

Conclusions: More than one third of all patients seeking psychiatric care have children, yet children's representatives and other staff members seldom meet them.

Key words: children's representatives, children of mentally ill patients, mental illness, mentally ill parents, resilience

\section{INTRODUCTION}

Children of mentally ill patients form a vulnerable group that has not been given adequate attention by institutions providing psychiatric care (Focht-Birkerts \& Beardslee, 2000; Ramchandani \& Stein, 2003). Studies have shown that children may develop satisfactorily despite a parent's mental illness, provided the home environment does not present high risks, hostile behaviour, or otherwise troublesome circumstances (Rutter \& Quinton, 1984). Research has indicated that nearly one third of all patients seeking psychiatric inpatient care have minor children (Östman \& Eidevall, 2005; Oppenheimer, 1979). Although greater attention has been directed toward children in the last few years, difficulties in identifying the children of mentally ill patients persist (Wang \& Goldsmith, 1994; Focht-Birkerts \& Beardslee, 2000; Östman, 2000; Göpfert et al., 2004).

In adult psychiatry, the fact that a patient may also be a parent is generally neglected, since therapy is directed at the treatment of a psychiatric illness. Discussing a patient's children, as well as parenthood in general, as well as the possible family consequences of psychiatric illness, is a delicate and complex matter.

The past 25 years have seen increasing reports of children who spend their youth and adolescence in households with mentally ill parents (Rutter \& Quinton, 1984; Dunn, 1993; Barnes \& Stein, 2000; 
Östman \& Hansson, 2002; Östman, 2008). Children have also become a more conspicuous part of adult psychiatric care through the establishment of support groups for children of mentally ill patients and training for those who provide psychiatric services to such parents.

\title{
Project Children's Representatives
}

A cooperative project was initiated between an adult psychiatry clinic and a unit for child and adolescence psychiatry (BUP) in a healthcare facility in the city of Lund in southern Sweden. The intention was to focus on matters concerning children of mentally ill patients. The children's representatives who participated were drawn from many professions.

Initially, lectures were given on the subject and a methodology was developed. As a result, a project named Children's Representatives, directed toward children whose parents were mentally ill, was established in 2001 as a part of the psychiatric services of Lund. In every adult psychiatry unit, one staff member was designate as a 'children's representative'. This person was given the task of attending to the situation of parents and children, as well as supporting colleagues who were treating such patients. Children's representatives were given in-service training on child development and the special needs of children with mentally ill parents. These representatives were expected to make their colleagues aware of this issue and provide expertise and encouragement. Emphasis was placed on sincerity and interest in the matter, irrespective of one's specific professional background.

The purpose of the project was to: (a) improve anamnesis and medical record-keeping with regard to the child encompassed by the project; (b) support the adult patient in his/her parental role; (c) inform the child about the parent's illness; (d) create a caring atmosphere for the child; (e) chart needs and arrange for resources; (f) establish contact with support groups; and (g) obtain assistance from BUP, as appropriate.

\begin{abstract}
AIMS
Using qualitative interviews, we sought to determine how children's representatives understood their task, and whether, as part of their duties, they were engaged in identifying children of mentally ill patients. An additional goal was to use the same kind of interviews to learn how other staff members conceived the role of children's representatives, and whether they thought this role would help to identify children of mentally ill patients.
\end{abstract}

\section{METHOD AND MATERIAL}

\section{Procedure}

Children's representatives and psychiatric co-workers were contacted in 2007 by telephone or email, informed about the study, and invited to participate. Interviewees were asked to choose where they would like to meet (this invariably turned out to be their place of work). The voluntary aspect of the study was emphasised. Printed information was sent to each potential participant in advance of the interview. At the interview, the aim of the study was again explained and written consent solicited. Each face-to-face interview lasted from 20 to 55 minutes and was recorded on mini-disc, with the approval of the participants. 
The interview was semi-structured and included a series of pre-established questions, supplemented by ancillary ones. As a pilot study to test the instrument, two trial interviews were conducted with staff members who would not be taking part in the actual project. After some small adjustments, the interview situation and the instrument were judged satisfactory. All interviews were administered by one of the authors (MA).

\section{Selection of children's representatives}

The study was carried out within the Psychiatric Services Division of Lund, in a unit with about 500 employees and a catchment area of approximately 185,000 people.

Thirty individuals of different professions work as children's representatives within the unit, three of whom were also associated with BUP. Four of the representatives were men. All of the Lund's children's representatives except the second author (MA) were invited to participate $(n=29)$. Seven of the representatives declined to participate, citing the fact that there were no patients with children in the unit where they worked. Thus, 22 children's representatives agreed to be interviewed, including two from BUP who had been assigned as consultants to the children's representatives.

\section{Selection of staff members}

Three employees from each of five different healthcare professions $(n=15)$, as well as an occupational therapist and a physiotherapist $(n=2)$, chosen at random from all the employees at the psychiatric clinic, were invited to join the study as staff representatives. Two managers from the adult psychiatric services also agreed to participate, making a total of 19. Three additional staff members who had been asked if they would participate in the study declined to be interviewed.

Participants were carefully chosen to represent in- and outpatient wards, as well as the psychosis and general psychiatric wards.

\section{Ethical considerations}

The study was carried out with the informed consent of all participants and with the understanding that the interviewee could at any time (and without need for explanation) terminate the interview. It was also made clear that the privacy of each interviewee would be assured by coding any identifiable data. Ethical approval for the study was obtained from the Regional Ethical Review Board at Lund University (LU 506/01). The head of the Adult Psychiatric Clinic of Lund gave permission to conduct the interviews.

\section{Data analysis}

All interviews were transcribed verbatim and coded to prevent any possibility of identifying the informants (Kvale, 1996). In the subsequent analysis, all interviews were read several times as a means of determining themes and patterns. The methodological point of reference for this study was taken from Naturalistic Inquiry (Lincoln \& Guba,1985), according to which triangulation and long-lasting engagement are two methods of insuring credibility in research. Our project was conducted by researchers with extensive experience in this area. The validity of the conclusions drawn from the interviews is enhanced by the presentation of direct quotations in the Results section and by comparisons with prior research in the Discussion. The criterion of generalizability is considered inappropriate for qualitative studies. In our inquiry we have tried to describe maximum variation, rather than seeking to verify a hypothesis. 


\section{RESULTS}

\section{The role of children's representatives}

In interviews, children's representatives described how they perceived their role as follows: 'Emphasize the child's perspective', 'Stimulate colleagues by asking questions about families with minor children', and 'Keep up to date'. Some interviewees stated that they had been inadequately prepared for their task. Others were of the opinion that the role assigned to them was 'fuzzy' or vague in certain ways. Representatives also observed that there were staff members at the unit who knew nothing of the role of children's representatives.

Half of the 22 children's representatives interviewed stated that they had shown interest in the project when management first informed them of it at a staff meeting. One third had been asked to take on the duty by colleagues. Most of the children's representatives interviewed were trained social workers. They declared that changes in adult psychiatry over the last few decades have helped emphasise their role by focusing not only on the needs of adult patients, but also on those of children of patients with severe mental illness. Along with the emergence of designated children's representatives, additional staff training was cited as contributing to a wider understanding of a family's situation where mental illness is concerned. One of the representatives interviewed remarked that in calling attention to the needs of children, the project elevated the topic to a certain importance.

A number of staff members who participated in the interviews commented that the role of children's representatives was unclear and that their duties were seldom discussed during work sessions. On the other hand, approximately half of the interviewees indicated that they did have a clear perception of the representatives' task, namely, to look after the interests of children. Some staff members said they had difficulty in separating the role of children's representative from that of professional social worker.

All children's representatives interviewed felt supported in their role by their colleagues on the team or by their unit. They also all thought staff considered the children of patients important, even though this was not always an issue with much visibility, since no children were actually living with the patients. The children's representatives reported that no other staff members on the team explicitly opposed the project, although some representatives mentioned experiencing difficulty in raising the topic with colleagues at treatment conferences. As one person expressed it: 'Sometimes I find it hard to ask, "But how are the children?"”

Several children's representatives felt that the guidance they had received from BUP was of great help and that cooperation with this unit, as well as with social services, had increased. One representative recalled a very positive response when a question about children was raised: 'Oh, how good you brought that up!' Two representatives related how much interest and concern children evoked among staff members in a psychiatric ward.

Several interviewees, both among children's representatives as well as staff members, believed management had not provided clear instructions on the role of children's representatives, nor had they formulated a consistent staff policy on how they should attend to children of mentally ill patients. As a result, it was left up to each unit or individual staff member to deal with the issue on their own. For example, if the head of a unit (or the chief physician-in-charge) was not interested in this aspect of caregiving, there might be conflict among the staff. Some interviewees suggested that wards that mainly worked with psychotic patients seemed to pay more attention to children and families than was the case in general psychiatric units. 


\section{Talking with patients about their children}

The majority of the children's representatives interviewed recalled that parents spontaneously told them about their children and the concern they felt for them. The interviews mentioned representatives encouraging patients to observe the effect on their family and children when they do not feel well mentally. Such suggestions generated positive feedback. Other representatives reported that patients worried about their children thinking that they were 'different'. They blamed themselves for not being adequate parents. One interviewee noted: 'If you get sick and are a parent that is a lot for you to handle... but if you are mentally ill and worry about not being able to cope with being a parent, it is even worse.... and yet you still have to be a mum or dad, no matter what.'

Some representatives had their doubts about talking with patients about their children. One remarked that when a woman with children seeks psychiatric help, therapists tend to question her more about her role as a parent than treat her for psychiatric issues. Another representative observed that some patients feared if they spoke about their children or invited them to the clinic, they might be reported to a social welfare agency. '[They feel that] if you get into their files, you'll never get out again. It's a very negative situation, so you get frightened.'

Staff members believed that patients with children who are involved in a divorce or in a custody battle might be afraid that their mental illness will be held against them. Such patients might be reluctant to involve their children in their treatment or to express themselves freely to a therapist under the circumstances.

\section{Few children visit the psychiatric services or are seen by professionals}

Interviews with children's representatives revealed that children rarely accompanied their parents to the psychiatric centre when the latter sought in- or outpatient care. One of several explanations given for this was that the psychiatric centre was only open during the daytime, while children are at school or in day care. However, patients who had recently given birth more commonly took their infants to the clinic with them. Other patients thought that children would not be welcome in the turbulent setting of the wards. Instead, they told their children to wait for them in the visitors' room outside the ward when they came to visit. In some wards children were not permitted to see their parent's living quarters for what staff cited as 'reasons of other patients' privacy'.

Most representatives said they had not encountered many children of mentally ill patients, either because of the patient's age or the fact that many patients had suffered from their psychiatric illness for a long time. One representative referred to the fact that her work was in the realm of adult psychiatry, where children of patients were not prioritized and the treatment of families was not involved. The thought of having children present in the treatment room also made some representatives uncomfortable.

Certain representatives admitted feeling uneasy talking with children of mentally ill patients. As one representative explained: 'I would be afraid of making things worse or worrying them more because I feel that I am not used to talking with children professionally. ... I think I would rather leave that to someone who knows how to do it.' Other interviewees, however, said they had no problem talking with children about their family situation and their parents' mental illness.

Many staff members said they also met with or spoke to few children because they feared it might lead to a discussion of things they would not know how to handle. They cited their lack of training in conducting child- and relative-orientated conversations that could facilitate the treatment process. Some staff interviewees felt the patient was sometimes disturbed by the presence of a child. Others patients appeared to have deliberately brought their child along to avoid talking about issues for 
which they were being treated. Several other staff interviewees recalled situations where they had made efforts to get in touch with a patient's children, but the patient resented their involvement.

\section{Children's representatives identify children of mentally ill patients}

Most interviewees agreed that their function as children's representatives brought more attention to bear on the children of mentally ill patients. As one representative commented: 'I think the important thing is to have one or two children's representatives in every unit whose responsibility it is to find out if there are children in a family. Then the plan will work.'

A number of children's representatives indicated that knowledge gained from training sessions had given them more confidence in better advocating for children's needs during conferences and on rounds. Representatives felt they could be useful in facilitating contact with children's support groups, social services and BUP - something they had overlooked earlier but now considered helpful in carrying out their duty.

A minority of children's representatives said they did not need to be encouraged to pay any more attention to children of mentally ill patients than before, since their professional roles as trained social workers already made them attend to this. Some suggested that taking into consideration the child's perspective and the family situation is 'fashionable nowadays', and this might be contributing to the improved scrutiny of children within families.

Many representatives said they thought the role of a children's representative would eventually disappear as the child's perspective becomes more and more integrated into family-orientated care. All agreed that identifying and supporting children of mentally ill patients was every caregiver's responsibility, although the degree of support a children's representative could offer might depend on their prior professional training.

Some staff members stated that they found it helpful to have children's representatives point out that children were involved in a case. Several interviewees agreed that such representatives gave children more visibility.

\section{DISCUSSION}

\section{The role of children's representatives}

As various studies have shown, one third of all patients seeking psychiatric inpatient care, and almost every second patient in outpatient care, are parents (Oppenheimer, 1979; Östman \& Hansson, 2002; Östman \& Eidevall, 2005). One way of providing patients in psychiatric services with greater understanding of their children is by means of children's representatives. In our project, which enlisted the aid of different occupational groups, we examined by means of qualitative interviews how such children's representatives and other staff viewed the endeavour. From descriptions given by the representatives regarding what they considered their task and how they carried it out, it appeared that they were guided by instructions they received from clinical management. On the other hand, some children's representatives characterized their role as 'fuzzy' and indistinct, perhaps as a result of general uncertainty as to the significance of their position within the sphere of psychiatric activity.

According to those we interviewed, it would have been desirable to have management exercise more control over the project; several children's representatives were disappointed that management's interest seemed to fluctuate since the project's inception. It was felt that management might 
be to blame for some of the difficulties faced by children's representatives and should have better prepared them to care for those who are mentally ill. Children's representatives indicated they were more confident talking with parents about their children after having received training. Similarly, they were then in a position to participate with other children's representatives in discussions. Some said they needed more help in managing family- and child-related treatment plans. Others wished for greater knowledge and guidance so they could fulfil their duties with more confidence and be able to justify their task.

Although most representatives thought their own working team had a positive attitude toward their responsibilities, they nevertheless questioned how firm this commitment was. Whether this affirmative view of working with children of mentally ill persons was due to the representatives themselves, or was a sign of the times, the interviewees, both the representatives and other staff members, could not say.

\section{The patient-centred tradition in psychiatric services}

Several co-workers, both staff members and children's representatives, pointed out that the tradition in adult psychiatry of working one on one with patients may have rendered collaborating with a colleague or meeting a patient's family unfamiliar territory. They spoke of how they were preoccupied with a patient's psychiatric symptoms; after dealing with these, they found it hard to adapt to handling family and children's issues. In addition, they expressed uncertainty about the way to approach children of mentally ill patients in a natural manner, and wondered how they could discuss family matters with parents and not put them off when it came to their individual therapy. In cases where a patient is unaware of his/her children's predicament, the therapist may need to go outside the framework of psychotherapy and bring the children into the picture. This may cause conflict among staff members trained to act within an individual treatment frame of reference. On the other hand, it may also cause staff members to consider the advisability of integrating family therapy methods into adult psychiatry.

Some children's representatives appear to have succeeded in bringing the perspective of the child to the psychiatric unit by establishing an active children's file and inviting representatives of social services to speak at in-service training sessions. Others have established separate children's rooms, furnishing them with toys so that children will have a pleasant atmosphere in which to play while visiting a parent who is hospitalized for mental illness. Despite the children's representatives' project, however, psychiatric care for adults does not seem to be a very child-friendly environment at present.

A care provider wishing to assist a family must be thorough and forthright enough to inquire after children. Recent literature on how children experience a parent's illness (McConell et al., 2006; Östman, 2008) confirms that this situation leaves the children feeling very lonely. At the same time, it has also been shown that patients with children frequently wish to discuss concerns they have for their offspring (Wang \& Goldsmith, 1994). There are models available for facilitating conversation in this area (Beardslee, 2002). These would be of great value in patient-centred treatment of those who have children. Although it may be difficult to talk to mentally ill parents about their children, the topic cannot be avoided. Nevertheless, in our study both children's representatives and other staff members continued to find it difficult to ask questions regarding children under such circumstances.

It is evident from the data presented that the role of children's representatives is not well defined, raising the issue of whether having them is the most useful way of addressing children's needs. 
It may be that assigning special representatives to address the needs of children may lead other staff members to feel absolved of such responsibilities. In interviews, both children's representatives and staff members stated that they felt it essential to personally meet with the children of patients to ensure that their needs are being met. Since the aim of psychiatric services is to enable adult patients and their families to live as good a life as possible, the cooperation of various social agencies is necessary. Child and adolescent social services must go hand in hand with adult psychiatric treatment if children are to be adequately cared for, despite their parent's illness.

\section{Methodological issues}

The fact that the interviewer herself was a children's representative made it easier to understand what the informants were describing. On the other hand, it required extra vigilance on the part of the interviewer not to involve personal views in the matter. Moreover, the fact that the interviewer was affiliated with the clinic may have made interviewees feel they were under scrutiny. As no institutional link existed between interviewer and informant, this risk was regarded as negligible. The participation of the first author (MÖ), who was unaffiliated with the psychiatric services department (although she had extensive experience in quantitative and qualitative research methods), may have decreased any feeling of dependency that might otherwise have been present, while at the same time increasing the credibility of the analysis.

\section{CONCLUSION}

Studies have shown how vulnerable children of mentally ill patients feel when their parent's care provider takes no notice of them (McConnell et al., 2006; Östman, 2008). While in principle instituting a corps of children's representatives may remedy this situation, an attempt to translate such a programme into practice indicates that obstacles persist. Our findings show that much remains to be done by way of clarifying the role of children's representatives and the benefits they might bring.

Other providers of psychiatric services considering a similar initiative might make it a priority to educate their entire staff on the needs of children of severely mentally ill patients. This would enable all psychiatric personnel to have the capacity to support those of their clients who are parents and, at the same time, include their children, thus securing the integrity of the family.

\section{ACKNOWLEDGEMENTS}

We wish to express our gratitude to all those who agreed to be interviewed for our research project. We also wish to thank the Vardal Foundation for the funding that made this study possible (B2005-038).

\section{REFERENCES}

Barnes, J. \& Stein, A. (2000) Effects of parental psychiatric and physical illness on child development. In New Oxford Textbook of Psychiatry (eds M.G. Gelder, J. Lopez-Ibor \& N. Andreasen). Oxford: Oxford University Press. Beardslee, W.R. (2002) When a Parent is Depressed. Boston: Little, Brown and Company. 
Dunn, B. (1993) Growing up with a psychotic mother. American Journal of Orthopsychiatry, 63(2), 177-189.

Focht-Birkerts, L. \& Beardslee, W.R. (2000) A child's experience of parental depression: Encouraging relational resilience in families with affective illness. Family Process, 39, 417-434.

Göpfert, G., Webster, J. \& Seeman, M. (eds) (2004) Parental Psychiatric Disorder. Cambridge: University Press.

Kvale, S. (1996) Interviews: An introduction to qualitative research interviewing. London: Sage.

Lincoln, Y. \& Guba, E. (1985) Naturalistic Inquiry. London: SAGE.

McConnell Gladstone, B., Boydell, K.M. \& McKeever, P. (2006) Recasting research into children's experience of parental mental illness: Beyond risk and resilience. Social Science \& Medicine, 62, 2540-2550.

Oppenheimer, R. (1979) Children of Psychiatric In-Patients. Proceedings from World Federation of Mental Health Congress on Children and Families.

Östman, M. (2000) Family Burden and Participation in Care (thesis). Lund: Department of Clinical Neuroscience, Division of Psychiatry, University Lund.

Östman, M (2008) Interviews with children of persons with a severe mental illness: Investigating their everyday situation. Nordic Journal of Psychiatry, 62, 354-359.

Östman, M. \& Eidevall, L. (2005) Illuminating patients with children up to 18 years of age: A one-day inventory study in a psychiatric service. Nordic Journal of Psychiatry, 59(5), 388-392.

Östman, M. \& Hansson, L. (2002) Children in families with a severely mentally ill member: Prevalence and needs for support. Social Psychiatry and Psychiatric Epidemiology, 37, 243-248.

Ramchandani, P. \& Stein, A. (2003) The impact of parental psychiatric disorder on children. British Medical Journal, 327(2), 242-243.

Rutter, M. \& Quinton, D. (1984) Parental psychiatric disorder: Effects on children, Psychological Medicine, 14, 853-880.

Wang, A-R. \& Goldsmith, V. (1994) Interviews of psychiatric inpatients about their family situation and young children. Acta Psychiatrica Scandinavica, 90, 459-465.

Margareta Östman, Professor, Faculty of Health and Society, Malmö University, Sweden.

Maria Afzelius, BA, Social Worker, Department of Psychiatry, Lunds University Hospital, Sweden.

Correspondence to: margareta.ostman@mah.se 